\title{
Continuous mentoring of medical students provides space for reflection and awareness of their own development
}

\author{
Susanne Kalén' ${ }^{1}$, Sari Ponzer1', Astrid Seeberger², Anna Kiessling ${ }^{3}$, Charlotte Silén ${ }^{4}$ \\ ${ }^{1}$ Department of Clinical Science and Education, Södersjukhuset, Karolinska Institutet, Stockholm, Sweden \\ ${ }^{2}$ Department of Clinical Science, Intervention and Technology, Karolinska Institutet, Stockholm, Sweden \\ ${ }^{3}$ Department of Clinical Sciences, Danderyd Hospital, Karolinska Institutet, Stockholm, Sweden \\ ${ }^{4}$ Department of Learning, Informatics, Management and Ethics, Karolinska Institutet, Stockholm, Sweden \\ Correspondence: Susanne Kalén, Klinicum, Jägargatan 20, Södersjukhuset, SE-118 83 Stockholm, Sweden \\ E-mail: susanne.kalen@ki.se
}

\begin{abstract}
Objectives: The aim of the study was to increase understanding of the meaning of continuous group and individual mentoring for medical students' personal and professional development.

Methods: A qualitative approach with individual student interviews and directed content analysis was chosen to investigate and interpret the meaning of mentorship.

Results: Five themes emerged: psychosocial support by the mentor, a relationship with a physician beneath the professional surface, space for something else, awareness of one's own development and reflection and learning with peers. The mentorship created a space where one could talk about 'the other things'. The relationship with the mentor was more personal than relations to teachers or supervisors.
\end{abstract}

During the group sessions the students could reflect and learn in interaction with others. Recurrent reflection about oneself and one's competences led to awareness of one's own development.

Conclusions: Combined group and individual mentoring creates space for reflection on the humanistic aspects of the professional role. A mentoring relationship can be supportive and personal without frequent meetings and knowing one another well. Continuity in mentorship helps students to reflect on and recognise their own professional development.

Keywords: Mentorship, undergraduate medical students, professional competence, professional development, self-assessment

\section{Introduction}

Mentoring has been recognised as an important part of medical education in recent years, but most countries still have no formalised mentoring programmes for medical students. ${ }^{1}$ In relation to current research, the phenomenon of mentoring in academic medicine needs to be explored more thoroughly to increase our understanding of its value. ${ }^{2}$ Different designs of mentoring programmes for medical students have been described and include various goals, such as providing career counseling, developing professionalism, supporting personal growth or increasing students' interest in research or a specific specialty. ${ }^{1}$ Most formalised mentoring programmes for medical students have been reported from the USA, but also from Germany, Switzer- land, Canada, the Netherlands and the UK.,3-7 Both formal and informal mentorship has been reported and the definition of mentor and mentoring varies, ${ }^{1,8}$ which sometimes makes it difficult to interpret the literature in the field. This paper contributes a deeper understanding of the meaning of continuous group and one-to-one mentoring, based on medical students' experiences.

To become a physician means more than learning basic scientific theory and clinical skills. The role of a physician also includes social and humanistic competences and skills which are more elusive to learn and assess in educational situations. These areas of competence are included in the concept of professional development which has gained 
increased attention in medical education and practice in recent years. Competences related to communication, collaboration, emotions, reflection, ethical obligations and humanistic judgement are emphasised ${ }^{9-11}$ and several methods are used for teaching in this field. Mentoring can be one method to promote students' development in these areas.

In a review of qualitative research into the meaning and characteristics of mentoring in academic medicine, the authors conclude that 'the largest gap in the existing body of research relates to the limited depth in which the phenomenon of mentoring in academic medicine has been explored. ${ }^{2}$ The review includes nine articles about mentoring and the participants were physicians, medical students, women and minorities. It focuses on mentoring characteristics, the relationship and barriers and strategies to improve mentoring. The authors claim that the lack of qualitative studies with rich descriptions reduces the ability to gain indepth understanding in this field. ${ }^{2}$

In order to develop meaningful mentoring programmes in medical education in the future, it is important to expand the understanding of mentoring with respect to students' development. In a former qualitative study by our group, medical students experienced one-to-one mentoring as a space alongside the educational programme where their motivation and belief in the future increased and their process of transition and feeling of belonging to a new community was enhanced. ${ }^{12,13}$ That form of mentoring created conditions for development of one's reflective capacity, emotional competence and the feeling of belonging to the community of physicians. ${ }^{12,13}$ But can other designs of mentoring programmes enhance students' development of these more 'elusive' competences in a similar way? This paper focuses on formal mentoring for medical students' professional and personal development. We have explored medical students' experiences of a combined group and one-to-one mentoring programme. A similar mentoring programme for dental students has been evaluated from the mentors' perspective. ${ }^{14}$ We have gone deeper into this from the student's perspective to better understand its meaning. Our understanding of mentoring corresponds well with SCOPME`s description of mentoring: "the process whereby an experienced, highly regarded, empathic person (the mentor), guides another individual (the mentee) in the development and reexamination of their own ideas, learning, and personal and professional development. The mentor, who often but not necessarily, works in the same organisation or field as the mentee, achieves this by listening and talking in confidence to the mentee."15

The aim of this study was to acquire a deeper understanding of the meaning of combined group and individual mentoring for medical students' professional and personal development.

\section{Methods}

The context of this study was a continuously ongoing mentoring programme in the 5.5 year-long medical educational programme at Karolinska Institutet. Small groups of medical students met their mentors once a term during a so-called workshop day. It was mandatory for students to participate, but their performance was not formally assessed. The workshop day had a main focus on humanistic elements of the professional role of a physician and consisted of three parts:

- Watching a video with a complex patient encounter and then reflecting in the group about the situation and how to handle it in a professional way as a physician. Scientific articles connected with the videos were read and discussed.

- Individual conversation with the mentor using a selfassessment form about professional competence, based on CANMed's professional roles of a physician..$^{10,16}$

- Gaining insight into the mentors' clinical work as physicians by following them in their daily work.

The role of the mentor in this programme was in line with SCOPME's description of mentoring. ${ }^{15}$ The mentors were physicians working mainly in hospitals. They followed the students during their education and led them through the workshop days as facilitators, not as a teacher or supervisor who had to check and assess knowledge and skills. The mentors were invited to educational meetings before every workshop day for their own preparation and training and for sharing experiences with other mentors. To become a mentor was voluntary and they were compensated for the time spent.

\section{Study design}

To deepen understanding of the meaning of combined group and individual mentoring in relation to professional and personal development, seen from the students' perspective, it was important to capture the students' own experiences. Therefore, a qualitative, interpretive method was chosen. Epistemological assumptions were taken from a constructivist perspective where reality is seen as being socially constructed. The research findings are regarded as being created in interaction between the researchers and the objects under study and do not reflect an objective truth, but can be transferred to other contexts. ${ }^{17}$

\section{Participants}

A purposeful and maximum variation sampling strategy ${ }^{18}$ was used to obtain breadth in data. Sixteen participants were assessed as a relevant sample size to get an appropriate and manageable amount of data. ${ }^{18}$ The participants were selected in several consecutive steps. First, an electronic 
questionnaire was sent to all of the 242 mentors and they were asked how they perform their workshop days and to state their age, gender, specialty and workplace. The response rate was $82 \%$. Mentors, as well as their student group, were regarded as eligible if they answered that their students were in semester 2, 4, 6 or 8 , if they, during the workshop day, participated in the intended activities, i.e. watching the videos, discussing the videos in a group and also had individual conversations with each student using the self-assessment form. A sample of 16 mentors from 102 mentors meeting these criteria was chosen with the aim to get as much difference as possible with respect to the combination of age, gender, specialty, workplace and the semester their students were in. Finally, the sample of the 16 students included in the study was chosen from these mentors' 55 students in the following way: one student per mentor, 4 students from each of the semesters 2, 4, 6 and 8 . Furthermore, the final sample of students was based on the students' age and gender with the aim to ensure as much variation and breadth as possible in the data.

Information about the study was sent by e-mail to the students and they were asked by telephone if they were willing to participate. Participation was voluntary and the students were informed that they could withdraw from the study at any time with no negative influence on their study results. The informed consent of all participants was obtained and they were guaranteed full confidentiality. Two of the initially included students declined to participate, so two new participants were chosen following the same sampling idea. The participants included were in the age range of 20-29 years and 50\% were women. This study was conducted according to the Helsinki Declaration and was judged by the Regional Ethical Review Board. The Board concluded that no formal ethical permission for this study was required according to Swedish law.

\section{Procedures}

Individual semi-structured interviews ${ }^{18}$ were conducted by SK with the 16 students during a period of 2.5 months. Questions in the interview guide were about their experiences of the workshop day, the group discussion, the relationship with the mentor, the individual conversations, the students' thoughts about their own development and their experiences from following the mentor in the clinic. The interview guide was piloted with one student interview. The interview was transcribed and discussed in the research group before the rest of the interviews were conducted. Together, the 16 interviews yielded 13 hours of recorded material, the shortest interview lasting 26 minutes and the longest 1 hour and 14 minutes. The mean length of the interviews was 47 minutes. Memos and own reflections were written down by the interviewer after each interview.

\section{Analysis}

An interpretive, directed approach to latent content analysis ${ }^{19,20}$ was used to extend our previous understanding of mentoring. A directed approach means that earlier research findings can be used to guide the initial coding process and the discussion. New codes and categories can contradict, refine or enrich earlier research or theories. ${ }^{20}$ The recorded interviews were transcribed verbatim and checked for completeness. SK read and listened to all interviews to become familiar with the data and took notes about the content. Memos and reflections were written down during the mean time. All interviews were read again and meaning units $^{19}$ were identified and highlighted. Meaning units were then condensed, entered into QSR NVivo 921 and sorted into three domains guided by the themes in our former study: space, belief in the future and transition. ${ }^{13}$ The unit of analysis for this paper was from the space domain; remaining data will be reported in a separate paper. Data were coded using predetermined codes with great openness for new codes for data that did not fit into the former coding scheme. ${ }^{13}$ All the predetermined codes according to the space domain were used, but for the main part of the data, new codes were created (Table 1). SK sorted and coded data manually in QSR NVivo 9.21 Codes were then categorised and interpreted into themes. ${ }^{19}$ Codes, categories and themes were discussed continuously in the research group during the process to ensure that they covered the data well and were internally homogeneous and externally heterogeneous. ${ }^{18}$ The researchers moved back and forth from parts to the whole until patterns and themes emerged.

\section{Results}

Five themes emerged about the meaning of continuous group and one-to-one mentoring. The themes are psychosocial support by the mentor, a relationship with a physician beneath the professional surface, a space for something else, awareness of one's own development and reflection and learning with peers. All themes are described separately below with illustrating quotes and are presented in Table 1 with underlying codes and categories.

\section{Psychosocial support by the mentor}

This theme describes the mentor as providing psychosocial support. The students experienced their mentors as being supportive, being role models, acting as sounding boards, listening interestedly and giving good advice. They clearly expressed that they felt trust and confidence in their mentors and in their knowledge and experience. It was relieving to talk with the mentor about worries and to get distance to experienced events.

\footnotetext{
"... term 4, it was. Then I was in a period when we had the mentoring meeting, when I questioned my career choice very much and the path I had begun, and this was exactly as we had begun to go out and meet patients. We had just started with our clinical practice, the last half of term 4, when I questioned myself very, very much. And ... then I had a very good conversation
} 
Table 1. Scheme of codes, categories and themes. Predetermined codes from the previous study ${ }^{13}$ are printed in bold

\begin{tabular}{|c|c|c|}
\hline Code & Category & Theme \\
\hline \multicolumn{3}{|l|}{ Relieving } \\
\hline Own and others' demands & The mentor has a supportive function & \\
\hline \multicolumn{3}{|l|}{ Support } \\
\hline \multicolumn{3}{|l|}{ Advice about study time contra time for other interests } \\
\hline \multicolumn{3}{|l|}{ The mentor gives advice } \\
\hline \multicolumn{3}{|l|}{ The mentor is a sounding board } \\
\hline Permitted to have another opinion & The mentor is as a sounding board and adviser & Psychosocial support by the mentor \\
\hline \multicolumn{3}{|l|}{ Listening mentor } \\
\hline \multicolumn{3}{|l|}{ The mentor asks questions } \\
\hline \multicolumn{3}{|l|}{ The mentor is a tool to come to one's own insight } \\
\hline \multicolumn{3}{|l|}{ Confidence in the mentor } \\
\hline Role model & Feel confidence in the mentor and his/her expertise & \\
\hline \multicolumn{3}{|l|}{ The mentor is experienced } \\
\hline The mentor is interested and engaged in the students & $\begin{array}{l}\text { The mentor shows interest and tries to arrange every- } \\
\text { thing in a good way }\end{array}$ & \\
\hline $\begin{array}{l}\text { Talk about social aspects of the professional role } \\
\text { Something else than the usual }\end{array}$ & $\begin{array}{l}\text { Space to talk about subjects not brought up otherwise in } \\
\text { the medical programme }\end{array}$ & \\
\hline Someone to talk to & Somewhere to talk on a more personal level & \\
\hline \multicolumn{3}{|l|}{ Getting more attention in the individual meeting } \\
\hline Do not bring up the same things in the group as individually & $\begin{array}{l}\text { Group sessions and individual meetings with the mentor } \\
\text { fulfill different functions }\end{array}$ & \\
\hline Do not bring up personal things in the group & & Space for something else \\
\hline \multicolumn{3}{|l|}{ Positive feelings about the workshop day } \\
\hline \multicolumn{3}{|l|}{ A nice break from the studies } \\
\hline \multicolumn{3}{|l|}{ An opportunity to think } \\
\hline No requirements for knowledge & A tree zone beside the medical programme & \\
\hline \multicolumn{3}{|l|}{ Nice meeting } \\
\hline \multicolumn{3}{|l|}{ Separate from the educational programme } \\
\hline \multicolumn{3}{|l|}{ Someone who has followed you for a long time } \\
\hline Less anonymous & $\begin{array}{l}\text { Safety with continuity throughout the whole medical } \\
\text { programme }\end{array}$ & \\
\hline \multicolumn{3}{|l|}{ A fixed point to come back to } \\
\hline To talk individually & A personal conversation & \\
\hline \multicolumn{2}{|r|}{ A porconal contact with a nhycician } & \\
\hline \multicolumn{3}{|c|}{ A personai contact witn a prysicician } \\
\hline \multicolumn{2}{|l|}{ The mentor is familiar with the educational system } & \multirow{6}{*}{$\begin{array}{l}\text { A relation with a physician beneath } \\
\text { the professional surface }\end{array}$} \\
\hline $\begin{array}{l}\text { Update each other about what has happened since the last } \\
\text { time }\end{array}$ & Someone who is familiar with one's life situation & \\
\hline \multicolumn{2}{|l|}{ Do not know the mentor very well } & \\
\hline Available mentor & $\begin{array}{l}\text { Have the opportunity to seek support from the mentor } \\
\text { between the meetings but do not }\end{array}$ & \\
\hline \multicolumn{2}{|l|}{ Could turn to the mentor } & \\
\hline $\begin{array}{l}\text { Closer to classmates than to the mentor } \\
\text { Have others to turn to }\end{array}$ & Prefer to turn to others to talk and get support & \\
\hline Reflection on own development & & \\
\hline $\begin{array}{l}\text { The mentor sees a difference from time to time - development } \\
\text { The mentor gives feedback }\end{array}$ & $\begin{array}{l}\text { Alarm bell indicating that something happens from one } \\
\text { time to another }\end{array}$ & $\begin{array}{l}\text { Awareness of one's own develop- } \\
\text { ment }\end{array}$ \\
\hline Motivated by setting goals & Motivation, engine for further development & \\
\hline Exchange with other students & The other students provide new perspectives & \\
\hline Reflection on experiences & Learning by reflection together with other students & \\
\hline Group discussions are good & Learning by rerlection togetner witn otner students & Reflection and learning with peers \\
\hline Good atmosphere in the group & Positive climate in the group & \\
\hline The function of the mentor in the group session & The mentor as a catalyst for the group & \\
\hline
\end{tabular}


with my mentor, and it was really so uplifting and I went away afterwards and was... what a relief that we could sort this out." (V0130001 T6)

The mentors were encouraging, gave confirmation and could also help the students to structure their studying better and discuss how to prioritise time. In these discussions the students could realise that private life and wellbeing had a connection to professional life and study results. The mentors were perceived as being interested in the students and making efforts to conduct the mentorship and the workshop days as well as possible. Some students believed they could have used the mentorship in a better way, but that it was their own responsibility to grasp that chance.

\section{A relationship with a physician beneath the professional surface}

The relationship with the mentor was experienced as being more personal than relations to other physicians they had met as teachers or supervisors. It was a relationship with the person behind the physician's professional surface. Even if they did not have a close relation to the mentor (they met just once a semester), the mentor was perceived as an appointed person who listened and talked to them in a personal way, the only person who followed them throughout the whole medical programme.

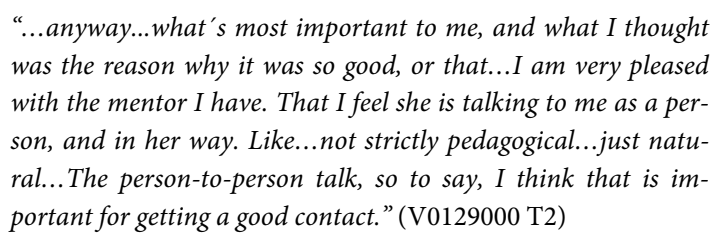

The students felt they were seen by someone who understood their life situation. The mentor was experienced as having more knowledge about the educational programme than other physicians in their social network, if they had any. It was appreciated and it felt safe to have a personal relationship with a physician, a future colleague, and to have a contact in the healthcare system.

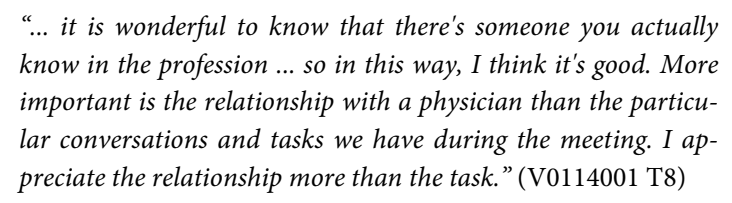

During the individual meetings the students were given full attention by the mentor and they could open up and talk about more personal things they did not want to share with the rest of the group.

\footnotetext{
"...the private things come a little easier, to really say what you think about yourself, and you can talk about so much personal stuff you do not want to tell the group." (V0116001 T4)
}

The relationship was described as being both personal and distanced. The students were invited by their mentors to contact them whenever they needed to between the workshop days, but even if the students could open up and talk with the mentor in a very personal way during these days, the mentor was not the first person they would contact for support between these meetings. In such situations they would rather seek support from relatives, classmates or other persons in their social network with whom they had a closer relationship.

“...if something happened...during the semester...he is not the
first person I would call to ventilate or talk to at first hand. I
wouldn't have any problem to tell him later that something had
happened and discuss it with him when you have the individu-
al conversation, but... we haven't got that...contact or relation-
ship that I would...that I would call him." (V0120500 T8)

Space for something else

The mentorship and the workshop days were experienced as a space to talk about 'the other things', the subjects that are not talked about anywhere else in the educational programme. During these days they could discuss social aspects of their professional role, such as ethics and morals, both in the group and individually with the mentor. They could talk on a more personal level about different experiences, from both their clinical and private life, and the mentor was regarded as a person they could ask 'the other questions.'

"... I think it's nice to have a ... to be with, to have a mentor who
you can ask about these social issues. Because you don't do that
at the primary healthcare centre...... I'm not very comfortable
discussing that I don't like to talk to elderly people in front of
the group, for example. But I can bring it up with him, and he
takes it gracefully. Mm, so it is that you bring up other issues."
(V0114000 T4)

The workshop days were positive breaks to catch your breath during your ordinary studies, a place to think 'outside the box' without requirements to perform or being judged. It felt safe to have a fixed point to come back to continuously during the educational programme, where it felt more familiar and less anonymous.

\footnotetext{
"It can be nice to get away from routines sometimes if you have heavy lectures, or if you have heavy clinical assignments, so I think it might be nice to have a day when you can do something else." (V0116000 T6)
}

The different parts of the workshop day seemed to offer different forms of space for the students as they brought up different issues in groups and individually with the mentor. The students looked forward to the workshop days, to meeting the mentor and the other students and getting a taste of the clinical workplace. However, there were also students who felt stressed about spending a whole day just 
sitting and talking if they were pressed for time and would have preferred to study for the next examination. They had these feelings especially before the workshop day; afterwards they often felt it had been worthwhile.

\section{Awareness of one's own development}

Continuity and recurrent reflection about oneself with the mentor led to awareness of one's own development.

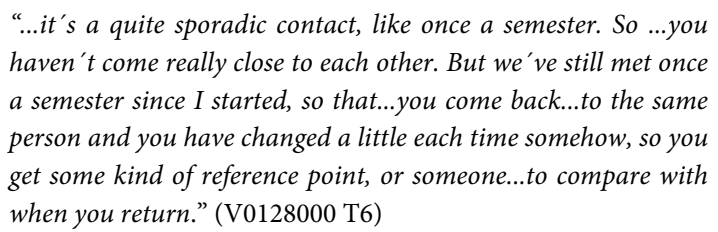

When discussing the self-assessment form individually with the mentor the students reflected on their development from both personal and professional aspects. They became aware of their own personality, understanding of oneself and how one works. The self-assessment form itself was not experienced as enhancing development. The students did not always think of the goals in the plan between the workshop days, but by discussing them with the mentor once a semester, it was an awakening that something had happened since the last time. The mentor could see differences, give feedback and remind the student of earlier discussions about strengths and weaknesses. This difference was not seen among the students themselves since they develop continuously side by side with about the same progress.

\footnotetext{
"...The most positive thing, I think, is just this that you actually ...that you actually notice ... differences from time to time when you compare these forms, self-assessment forms. Things have happened during the last half year and, compared to the half year before that. And ... and I do not think I had... had understood that... that there is actually progress, without those forms. Because ... well, it's hard to understand that you have actually learned things..." (V1205000 T8)
}

Some students said that the plan for improvement motivated them to try to reach the goals by the next time, especially if the goals were very concrete. Other students said that they never thought about the goals between the workshop days, but that the goals probably existed hidden somewhere and affected their development unconsciously.

\begin{abstract}
"... about the self-assessment specifically, I said I needed to practice this and then think about it. But that disappears pretty quickly, but it is possible that it remains in the unconscious... that you, when you get back there next semester you realise that, yeah, I've actually improved in this." (V0116001 T4)
\end{abstract}

\section{Reflection and learning with peers}

The group created space for reflection and learning in interaction with peers. The students appreciated discussing difficult issues such as behaviour and ethics in the group. They could reflect together on situations in the videos and also connect to their own experienced situations, from both their private and professional lives. They had to put words to their own thoughts and explain to others.

“... just to put it into words, it feels like you think it over more
thoroughly. And with the confirmation of others, it feels like you
... maybe I don't think in such a crazy way after all. Well, I
don't know, it'll be like a deeper... you have to think and you
have to put it into words, then you learn better somehow."
(V0130000 T8)

By sharing experiences and thoughts with peers, the students could see situations from different points of view, without being judged right or wrong. The group contributed to the confirmation of thoughts as well as providing other perspectives about the discussed situations.

"...I think it is better to sit in a group of this type... when discuss-
ing these more difficult questions. And it's pretty good that it is
people you do not hang around with every day, so you get some
other perspectives and hear some other opinions. So the group
discussions, I think, have been very good."(V0210000 T6)

The students described the atmosphere in the group as permissive, like talking with colleagues in a relaxed way. In these discussions the mentor acted as a catalyst driving the discussions forward, asking open questions and ensuring that everyone participated. Sometimes the mentors also contributed to the discussion with new viewpoints and perspectives or their own thoughts and experiences from their professional life.

\section{Discussion}

Continuous group and one-to-one mentoring with this type of design created opportunities for psychosocial support and having a personal relationship with a physician and it provided space for something off the beaten path, for self-reflection and awareness of one's own development and for reflection and learning with peers. The results are discussed with a focus on relation, reflection and continuity, and we have also referred to our earlier study about one-toone mentoring. ${ }^{13}$ Experiences of psychosocial support by the mentor, a personal relationship with a professional and space for something else were found in both forms of mentoring, but in different depths and characteristics. Novel findings about the meaning of mentorship were the awareness of one's own development and reflection and learning with peers.

The personal connection with a faculty member is an essential element for students in a mentoring relationship ${ }^{22}$ and students in this study also emphasised that the personal connection with a physician was important and meaningful. They experienced psychosocial support from the mentors and appreciated having a personal relationship with a physician. The students were seen and treated as the persons they are, not just a student among others, and they expressed this as being significant for this relation 
compared to other faculty relations. The mentors were perceived by the students as appointed persons they had special access to as part of their education. They described the relationship with the mentor as personal and penetrating the professional surface, which seemed to be important for their understanding of how to combine oneself as a person with the role of being a physician. Even in one-toone mentoring students reported they had a personal relationship with the mentor and got 'behind the professional mask. ${ }^{33}$ Therefore, it was surprising that the students in this study experienced that they had a personal relationship with the mentor, even if they did not meet very often and described the relation as being both personal and distanced. That suggests that formal mentoring with allocated mentors, not chosen by the students, and a long time between meetings can nevertheless effectuate the experience of having a personal relationship with a professional. This also suggests that it is possible to meet a professional on a personal level without having the feeling of closeness. Discussing complicated psychosocial patient encounters, humanistic competences of a physician and assessing one's own strengths and weaknesses may have contributed to the experience of having a personal relationship since it led to other subjects and to talking in another way than the usual one. In our previous study the students expressed a feeling of becoming a member of a new community, they described it in terms of fellowship, being a partner and belonging, ${ }^{13}$ which was not found in the same way in this programme. A possible explanation for this difference is that the one-toone mentoring programme ${ }^{13}$ took place from semester 5 to 8 when the students had come farther in their transition process $^{23}$ and could more easily identify themselves with the mentor and the professional role of a physician with feelings of partnership and belonging. Students in this programme met their mentor already in their first semester when they were at a very early stage in their education and the identifying process of becoming physicians, and that distance between being a newcomer and being more experienced may persist throughout the whole relationship. It is not known how the relation was experienced by the mentors in this programme and if its value was mutual. However, a successful mentorship relation requires mutual interest and active participation from both parties. ${ }^{24}$ Our results imply that continuity is of great importance for building mentoring relations and for maintaining mutual interest over time. The mentorship created space for reflection in different ways: reflection on experiences, reflection on oneself and one's development, reflection with others and reflection on behaviour and personality. The students were stimulated to reflect both within the group and individually with the mentor. Reflective practice has been described as an essential attribute of competent healthcare professionals ${ }^{25}$ and to learn from experience and reflect are defined as professional competences of a physician. ${ }^{9,26}$ Reflection is needed to learn from experience and to develop and maintain competence in life-long-learning. ${ }^{25}$ Reflection is a part of the process where students' experiences turn into new understanding. ${ }^{27}$ The group sessions, where students shared experiences and thoughts with one another, created space for reflection and for seeing situations from different perspectives. They could reflect on and learn from their own and others' experiences. The videos stimulated to reflection on the physician's behavior in particular cases, on how to interpret and evaluate the situations and how to act as a physician in a similar situation. We see the mentoring programme as promoting space for reflection on action and for enhancing development of the 'reflective practitioner'. ${ }^{25,28}$ Reflection and evaluation of one's work are also emphasised as key factors for development of one's professional profile. ${ }^{29}$ Reflection during undergraduate education seems to be important for reaching the goal of being a practitioner who reflects over his work with awareness of his or her own beliefs and values. The students experienced an open and permissive atmosphere during the workshop days without any pressure to have the correct answers or of being assessed. The individual part of the mentorship offered an opportunity to talk about things they did not want to share with the rest of the group, such as emotions, doubts and anxiety. Reflection leads to new learning only if feelings and emotions are involved in the process. ${ }^{30}$ To be scrutinised by others can inhibit reflection and therefore a protected environment with confidentiality and trust is required to achieve a 'good reflective space'. ${ }^{30}$ Space for development of reflective competence was also enabled by one-to-one mentoring. ${ }^{13}$ We see the mentor's role as an essential factor for creating this free and safe space for reflection, where one can bring up feelings and emotions. To create such space requires that the mentors do not monitor or assess the students' performance. We think that students with no mentoring during their training lack this space where they can talk on a personal level, free and relaxed, with a professional about 'those other subjects.' Since the different parts of the workshop day created different opportunities for reflection, we would argue that individual mentoring cannot be replaced by group mentoring or the opposite.

Individual conversations with the mentor and continuous self-assessment stimulated the students to reflect on themselves and they became aware of their own development. Continuity in mentoring meetings provided an opportunity to compare one's self over time, to get feedback from the mentor and discover changes and development since the last meeting. A long time between the meetings did not seem to be a disadvantage in this respect, but rather the opposite. The mentor was the only person connected to the educational programme who followed the students throughout their education. We mean that continuity in the mentoring relationship and recurrent meetings during a long period of time facilitated the students to gain insight into and understanding of their own development. 
It was interesting to note that students' attitudes to the mentoring programme varied. Some expressed the value of the mentorship clearly, while others did not see the value of it until the interviews were completed and they had reflected on its meaning. This type of activity offers and requires something else than what students are used to encountering in the more traditional parts of medical education. Therefore, it is important to prepare mentors to support and challenge students to discover these aspects of the medical profession which are not primarily connected with medical knowledge and clinical skills. In this programme the mentors were invited to recurrent educational meetings aimed at training them to support students in these psychosocial and humanistic areas. Unfortunately, some mentors had difficulties to secure time to participate in these meetings, which is an organisational problem worthy of attention.

\section{Limitations of the study}

The strength of this study was the comprehensive sampling process which gave a wide variety of participants and breadth in the data. Out of all 242 mentors, 102 answered they had tried to fulfil the intentions of the programme, which were the criteria for making their students eligible to participate. No students in semester 9-11 were available since the mentoring programme had not yet been in progress so long; therefore, experiences from the latest phase of the programme are missing. A possible limitation was that only one of the researchers had total access to data entered into NVivo. For visibility and transparency, the transcribed interviews and the organised data in NVivo were printed out and discussed in the research group in all steps of the analysis. It may have facilitated and strengthened the process if all researchers had had access to NVivo, but this was not experienced as a disadvantage in the group. Several strategies were taken into account to ensure credibility and trustworthiness. Current documents about the programme were read as a first step to develop familiarity with the field. ${ }^{31}$ Furthermore, a focus group interview with students and two individual interviews with mentors were held for the same reason. Other strategies for achieving credibility were investigator triangulation ${ }^{18}$ and frequent debriefing sessions in the research group ${ }^{31}$ to check that the process proceeded according to the aim. Transferability to other situations was intended to be accomplished by a rich description of the context and methods. ${ }^{18,31}$

\section{Conclusions and implications}

Continuous group and one-to-one mentoring, including several given components, provided medical students with opportunities and space in different meanings: for psychosocial support, for having a personal relationship with a physician, for something off the beaten path, for self-reflection and awareness of one's own development and for reflection and learning with others about humanistic aspects of the professional role. The role of the mentor, not to monitor or assess the students' performance, seemed to be important for creating this space. A mentoring relationship can be established on a personal level without frequent meetings and knowing each other well. The group and the individual parts of the mentorship contributed to space for reflection in different ways, for which reason the individual part cannot be replaced by group mentoring. Continuity in the mentoring meetings helped students to discover their own professional development.

\section{Acknowledgements}

The authors thank all interviewed students, the mentors who responded to the survey and all other collaborators who contributed to the implementation of the study. This work was made possible by funds granted by the Medical Education Programme at Karolinska Institutet and by ALF, the Regional Agreement on Medical Training and Clinical Research between Stockholm County Council and Karolinska Institutet.

\section{Conflicts of Interest}

The authors declare that they have no conflict of interest.

\section{References}

1. Frei E, Stamm M, Buddeberg-Fischer B. Mentoring programs for medical students - a review of the PubMed literature 2000-2008. BMC Medical Education. 2010;10:32.

2. Sambunjak D, Straus SE, Marusic A. A systematic review of qualitative research on the meaning and characteristics of mentoring in academic medicine. Journal of General Internal Medicine. 2009;25(1):72-8.

3. Buddeberg-Fischer B, Herta KD. Formal mentoring programmes for medical students and doctors - a review of the Medline literature. Medical Teacher. 2006;28(3):248-57.

4. Indyk D, Deen D, Fornari A, Santos MT, Lu WH, Rucker L. The influence of longitudinal mentoring on medical student selection of primary care residencies. BMC Medical Education. 2011;11:27.

5. von der Borch P, Dimitriadis K, Stormann S, Meinel FG, Moder S, Reincke $\mathrm{M}$, et al. A novel large-scale mentoring program for medical students based on a quantitative and qualitative needs analysis. GMS Zeitschrift für Medizinische Ausbildung. 2011;28(2):Doc26.

6. Meinel FG, Dimitriadis K, von der Borch P, Stormann S, Niedermaier S, Fischer MR. More mentoring needed? A cross-sectional study of mentoring programs for medical students in Germany. BMC Medical Education. 2011;11:68.

7. Scheckler WE, Tuffli G, Schalch D, MacKinney A, Ehrlich E. The class mentor program at the University of Wisconsin Medical School: a unique and valuable asset for students and faculty. Wisconsin Medical Journal. 2004;103(7):46-50.

8. Sambunjak D, Straus SE, Marusic A. Mentoring in academic medicine: a systematic review. Journal of the American Medical Association. 2006;296(9):1103-15.

9. Epstein RM, Hundert EM. Defining and assessing professional competence. Journal of the American Medical Association. 2002;287(2):226-35.

10. The CanMEDS 2005 Framework. The royal college of physicians and surgeons of Canada; [cited 25 September 2012]; Available from: http://www.royalcollege.ca/portal/page/portal/rc/common/documents/can meds/framework/the_7_canmeds_roles_e.pdf

11. Tomorrow's Doctors. Outcomes and standards for undergraduate medical education. General Medical Council, UK; 2009 [cited 25 September 2012]; Available from: http://www.gmc-uk.org/static/documents/content /GMC_TD_09_1.11.11.pdf.

12. Kalen S, Stenfors-Hayes T, Hylin U, Larm MF, Hindbeck H, Ponzer S. Mentoring medical students during clinical courses: a way to enhance 
professional development. Medical Teacher. 2010;32(8):e315-21.

13. Kalen S, Ponzer S, Silen C. The core of mentorship: medical students' experiences of one-to-one mentoring in a clinical environment. Advances in Health Science Education: Theory and Practice. 2012;17(3):389-401.

14. Stenfors-Hayes T, Lindgren LE, Tranaeus S. Perspectives on being a mentor for undergraduate dental students. European Journal of Dental Education. 2011;15(3):153-8

15. Standing Committee on Postgraduate Medical and Dental Education. An enquiry into mentoring: supporting doctors and dentists at work. A SCOPME report. London: Department of Health; 1998.

16. Karolinska Institutet. Medical programme, course webb. [cited 15 February 2012]; Available from: http://pingpong.ki.se/public/courseId/5588 /coursePath/5549/5586/ecp/langsv/publicPage.do.

17. Swanwick T. Understanding Medical Education - Evidence, theory and practice. West Sussex, UK: Wiley-Blackwell; 2010.

18. Patton MQ. Qualitative research \& evaluation methods. $3^{\text {rd }}$ ed. London: Sage Publications; 2002.

19.Graneheim UH, Lundman B. Qualitative content analysis in nursing research: concepts, procedures and measures to achieve trustworthiness. Nurse Education Today. 2004;24(2):105-12.

20. Hsieh HF, Shannon SE. Three approaches to qualitative content analysis. Qualitative Health Research. 2005;15(9):1277-88.

21. QSR International. NVivo 92011 [cited 15 February 2012]; Available from: http://www.qsrinternational.com/products_nvivo.aspx.
22. Hauer KE, Teherani A, Dechet A, Aagaard EM. Medical students perceptions of mentoring: a focus-group analysis. Medical Teacher. 2005;27 (8):732-4.

23. Allen VL, Vlert Evd. Role transitions: explorations and explanations. New York: Plenum Press; 1984.

24. Garmel GM. Mentoring medical students in academic emergency medicine. Academic Emergency Medicine. 2004;11(12):1351-7.

25. Mann K, Gordon J, MacLeod A. Reflection and reflective practice in health professions education: a systematic review. Advances in Health Science Education: Theory and Practice.2009;14(4):595-621.

26. Tomorrow's doctors. Recommendations on undergraduate education. UK: General Medical Council; [cited 25 September 2012]; Available from: http://www.gmc-uk.org/TomorrowsDoctors_2003.pdf_39262074.pdf.

27. Boud D, Keogh R, Walker D. Reflection: Turning experience into learning. London: Kogan Page; 1985.

28. Schön D. The reflective practitioner - how professionals think in action. England: Arena, Ashgate Publishing Limited; 1983.

29. Forslund K. Professionell kompetens. Fyra essäer om inlärning och utveckling för professionalitet. $3^{\text {rd }}$ ed. Linköping, Sweden: Linköping University; 1995

30. Boud D. Using journal writing to enhance reflective practice. New Directions for Adult and Continuing Education. 2001(90):9-17.

31. Shenton AK. Strategies for ensuring trustworthiness in qualitative research projects. Education for Information. 2004(22):63-75. 